\title{
Combining Insurance, Contingent Debt, and Self-Retention in an Optimal Corporate Risk Financing Strategy
}

\author{
Eugene Gurenko
Olivier Mahul
}

Insurance and Contractual Savings Practice

Financial Sector Operations and Policy Department

\begin{abstract}
:
This paper provides a conceptual framework for designing a comprehensive risk financing strategy for a firm using an optimal combination of three instruments: self-retention, contingent debt and insurance. Using an original conceptual model, the risk management decisions of the firm are first decomposed into two sets: choosing attachment points for each layer of financing utilized in the overall risk financing structure and then determining optimal risk allocation arrangements within each layer of risk. This model allows us to show how these optimal risk financing arrangements are driven by the costs of risk management instruments, the risk characteristics, and the firm's borrowing constraints. Finally, the paper provides an original perspective to think about optimal ex ante risk management strategies based on a combination of insurance, savings and credit at the micro or macro levels.
\end{abstract}

World Bank Policy Research Working Paper 3167, November 2003

The Policy Research Working Paper Series disseminates the findings of work in progress to encourage the exchange of ideas about development issues. An objective of the series is to get the findings out quickly, even if the presentations are less than fully polished. The papers carry the names of the authors and should be cited accordingly. The findings, interpretations, and conclusions expressed in this paper are entirely those of the authors. They do not necessarily represent the view of the World Bank, its Executive Directors, or the countries they represent. Policy Research Working Papers are available online at http:/lecon.worldbank.org. 


\section{Introduction}

The purpose of this paper is to devise an optimal risk financing strategy for an economic entity with a single risk exposure that seeks to reduce the volatility of its earnings without sacrificing profitability. While the universe of potential economic agents concerned with the design of an optimal risk financing strategy may include governments, households, and companies, the model and analytical conclusions presented in this paper are best suited for a firm. ${ }^{1}$ To arrive at the optimal risk financing strategy, we derive optimal combinations of three most common risk financing options that may be available to a firm such as selfretention, insurance and contingent debt under different assumptions about the pricing of these instruments and the variability of underlying risk.

While the existing literature provides only descriptive analyses of these post-loss financing instruments in the management of catastrophic risks (see, e.g., Swiss Re 1999, 2001, Jaffee and Russel 1999), this paper proposes an original conceptual framework to address this problem and offers an explicit guidance to corporate risk managers regarding the optimal combination of three risk financing instruments under different pricing and variability-of-risk scenarios.

In devising the analytical framework used in this paper, we assume that the firm's decisions on the design of the optimal risk management strategy are driven by the cost of its internal capital, the cost of its external borrowing, the cost of insurance, by the variability characteristics of the risk, and by the borrowing constraint. In an attempt to develop a dynamic analysis of the problem, we use a simple two-period model in which the risk-averse firm faces a single risk exposure at the end of the first period. The firm can purchase insurance and/or contingent debt and/or it can decide to retain a part of the risk in the first period, before the occurrence of a loss. However, to avoid unlimited borrowing and thus a potential default on its debt obligations, the firm faces a borrowing constraint that limits the amount of contingent debt it can assume to finance the risk. In the second period, following the loss and assuming the firm did resort to borrowing, it has to reimburse the full amount of the contingent loan.

Among the key advantages of the model is the ability to accommodate any type of the insurance or contingent debt financing contracts regardless of their coverage design characteristics. Such modeling flexibility allows us to distinguish between the two key issues confronted by the firm in the design of its risk financing strategy, which are:

- how to pick attachment points for each risk financing contract, and

- how to determine optimal risk-financing arrangements using different instruments within each layer of the risk financing structure.

Such a decomposition of the firm's choices in designing an optimal risk-financing strategy constitutes one of the key contributions of this paper.

The choice of the attachment points in the firm's risk financing structure is determined by the cost tradeoffs among different risk financing instruments. First, it is worth pointing out that if insurance and contingent debt are very costly for the firm, the optimal strategy would be to self-retain all the risk. On the contrary, if insurance is sold at an actuarially fair price, the

\footnotetext{
${ }^{1}$ However, with some minor modifications of assumptions used in the underlying model, the approach presented in the paper can become applicable in the case of governments, farmers, households or small businesses concerned with hedging their risk exposures.
} 
optimal strategy requires the purchase of the full insurance coverage. However, the base risk financing structure examined in the paper is more complex as it relies on the following assumptions: (i) both insurance and contingent debt are costly, and (ii) insurance is more costly than contingent debt, and (iii) the firm faces a borrowing constraint. Although the model does not allow to give an explicit definition of the optimal attachment points depending on these costs, it nevertheless enables us to determine the main structural features of the optimal risk management strategy under some basic assumptions.

Based on the broad contours of the risk financing program suggested by the model, we develop and test several risk financing programs. Under the base case scenario of a risk financing program suggested by the above described assumptions, it would be optimal to have four layers of stockpiled risk financing contracts. In the lower layer, Layer I, the firm retains 100 percent of the loss, as a consequence of (i). In Layer II, the optimal risk sharing arrangement relies on contingent debt and self-retention, as a consequence of (ii). In Layer III, self-retention, insurance and contingent may be part of the optimal strategy. In the upper layer, Layer IV, the loss is self-retained by the firm and/or transferred to the insurance company, as a consequence of (iii).

The final internal structure of each of four layers is also driven by two variables: the pricing of each risk financing instrument and the variability characteristics of the risk. In the case of insurance this twofold approach translates into breaking the insurance premium into two components. While the first one is a proxy of expected loss, the second one depends on the variability of loss, thus taking into account the cost the insurer's reserves (capital costs). These two components affects the structure of the layers in a different fashion. While both of them lead to complete self retention (insurance deductible) in Layer I and partial selfretention in Layer II, the insurer's cost of loss variability affects only the two upper layers. As a consequence, when the insurance premium is only proportional to the expected loss (the insurer does not charge for the variability of the loss), complete insurance coverage becomes optimal in layers III and IV.

The main contribution of this paper is to offer a detailed analysis and a mathematical algorithm to derive the optimal risk-sharing arrangements for each of the four layers of the assumed base case risk financing structure under some specific but plausible assumptions. In the course of this research we explicitly demonstrate the impact of costs for three different risk financing instruments and of the variability of the underlying risk on the ultimate design of the risk financing program chosen by the firm. In addition, we are able to study the impact of the borrowing constraints on the optimal risk-sharing rules.

This paper is organized as follows. Section 2 presents the conceptual framework which first describes the firm's modeled attitude towards risk. Then we examine the suitable risk financing products followed by the description of the multi-period approach adopted in this research. In Section 3, we derive optimal risk financing strategies under different costs and risk variability assumptions. Comparative static analyses of the main parameters are also performed. We also provide numerical examples to illustrate the impact of the instrument costs and risk variability on the optimal risk-sharing arrangements within each layer of risk financing structure.

In Section 4 we consider numerical examples to examine the impact of the insurance cost on the optimal risk-financing arrangements within each risk layer. Section 5 contains major results and conclusions of this research and discusses the next steps in developing analytical 
tools that can be used by risk managers to devise optimal risk financing strategies under different pricing and risk variability assumptions.

\section{The Conceptual Framework}

\subsection{An Economic Framework for Corporate Risk Management}

In this paper, our objective is to examine the key drivers of corporate decision making that underpin the firms' risk hedging strategies. In the optimization model developed for this paper we consider the economic behavior of a firm exposed to a risk of loss. If the firm is privately held, the owners' equity may be concentrated in the firm and thus the risk-averse behavior prevails. In the utility framework developed by Von Neumann and Morgenstern (1944), the firm's preferences towards risk are represented by an increasing and concave utility function of the firm's profits. Hence, the firm is an expected utility maximizer.

If the firm is publicly listed, the standard finance theory suggests that shareholders of the firm should be de facto risk neutral given their ability to diversify in well-functioning capital markets. Nevertheless, there are several reasons which may still make the firm risk averse. Such an apparent risk-averse behavior can be caused by the risk aversion of managers, the existence of asymmetrical tax treatment of profits and losses, high costs of financial distress

and restricted debt capacity (Smith and Stulz 1985), capital market imperfections (Greenwald and Stiglitz 1993), or information asymmetries that raise the cost of external funds relative to internal capital (Froot, Scharfstein and Stein 1993). The profit variability is costly for the firm due to deadweight costs that can be represented by an increasing and convex function of the firm's profits. Hence, the firm is an expected value maximizer where the expected profit net of deadweight costs is an increasing and concave function of the firm's profit.

In either case, the final wealth of the firm is mapped onto a strictly increasing and concave utility function indicating the presence of risk aversion. This intrinsic risk aversion provides the basic rationale for the firm's risk hedging that may involve a genuine risk transfer through insurance or risk financing in the form of contingent debt and self-retention.

\subsection{Description of the risk management products}

As has been already mentioned, the firm's ability to manage the variability of its profits can be exercised in three ways - (i) by utilizing the firm's equity capital to finance a retained part of the risk; (ii) by purchasing insurance and/or (iii) by borrowing through contingent debt.

Under the insurance policy, the firm pays a premium and receives an indemnity should a loss occur. The indemnity schedule may contain a deductible and/or coinsurance. The insurance premium is usually defined as the sum of the expected indemnity (pure premium), reserve loads, administrative costs and returns on equity. We assume that the premium is an increasing and non-concave function of the indemnity. In particular, this allows us to capture the insurer's risk surcharge included in the insurance premium due to the variability of the indemnity. The relationship is mathematically described by

$$
P=f(E I)+g(\operatorname{VarI}) \text { with } f(.) \geq 0, f^{\prime}(.)>0 \text { and } g(.) \geq 0, g^{\prime}(.) \geq 0,
$$

where $P$ is the insurance premium, $E I$ is the expected indemnity and $\operatorname{Var} I$ is the variance of the indemnity. The function $f$ is the part of the insurance premium, beyond the pure premium, that can be viewed as administrative costs. The function represents the cost implied by the variability of the insured loss. A particular case is when the insurance premium depends only 
on the expected indemnity, i.e., $g()=$.0 ; the insurance company does not charge any risk premium due to the variability of the indemnity payments.

The firm also has the opportunity to get access to capital following a loss through contingent debt. To arrange the post-loss financing on an ex-ante basis, the firm first pays a loan commitment fee and, in the event of a loss, it receives the full principal of the pre-arranged loan that will be repaid over time. To avoid a subsequent loan default, we assume that the maximum amount of the loan is limited by the firm's overall borrowing capacity.

The firm can decide to self-retain part of the risk. We assume that the loss is not higher than the initial wealth of the firm and, thus, the firm has enough equity capital to finance the entire amount of risk exposure, if it chooses so. Such an assumption, of course, is based on the premise that the firm's entire equity can be fully committed to risk-financing which by default makes self-retention the most flexible source of risk financing at the firm's disposal.

However, the model easily provides for introducing a binding constraint on the firm's level of risk retention.

It should be noted that in this framework the firm does not have any profit, i.e., it cannot build retained earnings on its balance sheet (thus increasing its equity) to deal with a possible future loss. We acknowledge that this assumption is restrictive, but this allows us to focus on the role of insurance and contingent debt as pre-loss and post-loss financing instruments. The role of future savings (retained earnings) is left to further research.

\subsection{Timing}

For the sake of simplicity, we consider a two-period, three-date model. However, this simple model will allow us to capture the main tradeoffs between risk self-retention, insurance and contingent debt that lead to optimal risk management strategies. On date 0 , the firm purchases an insurance contract (and pays the insurance premium) and/or a contingent debt (and pays the credit commitment fee). On date 1 , should a loss occur, the insurance indemnity is paid to the firm and/or a contingent loan is given. On date 2 , the firm fully repays the principal and the interest of the loan.

\section{Optimal Risk Management Strategies}

The design of optimal combinations of insurance, contingent debt and self-retention, solutions of a maximization problem, is derived using the optimal control theory. We impose weak constraints on the product design, e.g., non-negativity constraint. Such a flexibility in the design of risk sharing instruments allows us to distinguish between two sets of decisions variables made by the firm: attachment points and thus layers of risks in the firm's overall risk management structure, and risk-sharing arrangements within each of the four layers of the risk financing structure.

The theoretical assumptions and mathematical solutions of this problem are detailed in Annexes 1-4. The characteristics of the indemnity schedule under the insurance policy and the contingent debt are derived for the general case (see Appendix 2). Under additional, but realistic, assumptions of the firm's behavior, the optimal indemnity payment functions are then explicitly characterized (see Appendix 3).

\subsection{Optimal risk-sharing rules}

\subsubsection{Attachment points and layers of risk}


We assume that insurance is sold at a greater than actuarially fair price (e.g., the premium exceeds actuarial cost) and thus the optimal insurance contract design suggests a positive deductible $D_{2}>0$ If insurance were actuarially priced, however, the optimal risk management strategy for the risk averse firm would be to purchase full insurance coverage. The firm also pays a credit commitment fee to obtain the right for a loan at a pre-loss rate following the occurrence of a loss. It may thus be optimal to borrow if the loss is above an attachment point $D_{1}$. Furthermore, to avoid defaulting on the payment, the amount of the contingent debt must be below the upper bound defined by an attachment point $D_{3}$ above which the loss cannot be financed using the contingent debt. As has been mentioned earlier, the focus of the paper to examine the optimality of using contingent debt alongside other risksharing instruments such as self-retention and insurance under different pricing assumptions. While it is possible to find simple cases of the firm entirely relying on insurance or contingent debt, if it is "sufficiently cheap", and in the absence of borrowing constraints, the base case used in this paper assumes a risk financing strategy which utilizes all three financing instruments, e.g., contingent debt, insurance, and self-retention. We thus assume that insurance is also more expensive than contingent debt, implying $D_{2}>D_{1}$, but not "too expensive" so that $D_{2}<D_{3}$.

The base case optimal risk management strategy thus displays four layers: $\left[0, D_{1}\right],\left[D_{1}, D_{2}\right]$, $\left[D_{2}, D_{3}\right]$ and $\left[D_{3}, x_{\max }\right]$, with $0 \leq D_{1}<D_{2}<D_{3}<x_{\max }$ and $x_{\max }$ is the maximum possible loss. The optimal attachment points depend on the risk characteristics, the firm's attitude towards risk, the cost of insurance, and the cost of contingent debt. Although, the current model does not allow us to derive an explicit characterization of the attachment points, these

model limitations could be overcome by the use of stochastic simulation tools. This is left to further research. In this study our main focus is to derive explicit risk allocation arrangements between the three risk financing instruments within each layer of risk.

\subsubsection{Optimal risk-sharing rule in Layer I}

When the insurance policy is sold at a price greater than the actuarial fair price, then there exist a first layer of risk $\left[0, D_{1}\right]$, with $D_{1}>0$, which is fully retained by the firm.

\subsubsection{Optimal risk-sharing rule in Layer II}

Under the second layer of risk $\left[D_{1}, D_{2}\right]$, part of the loss is covered using a contingent debt, with the remaining loss being retained by the firm. The fraction of the loss within this layer covered by contingent debt is given by

$$
C D^{I I}=\frac{1}{1+\beta(1+r)^{2}} .
$$

where $\beta$ is the discount factor (i.e., $\beta=1 /(1+i)$ where $i$ is the cost of the firm's internal capital) and $r$ is the risk-free interest rate on the loan. 
The firm thus covers more (less) than $50 \%$ of its loss with contingent debt, i.e., transfers more (less) than $50 \%$ of the loss to the next period, if and only if $\beta<(>) 1 /(1+r)^{2}$, i.e., $1+i>(<)(1+r)^{2}$.

\subsubsection{Optimal risk-sharing rule in Layer III}

Under the third layer of risk $\left[D_{2}, D_{3}\right]$, all three risk management instruments at the firm's disposal are used. The degree of risk financing using the contingent debt is shown to be

$$
C D^{I I I}=\frac{\gamma}{\gamma+\beta(1+r)^{2}(1+\gamma)},
$$

and the extent of risk financing using the insurance policy is

$$
I N S^{I I I}=\frac{\beta(1+r)^{2}}{\gamma+\beta(1+r)^{2}(1+\gamma)}
$$

where $\gamma \geq 0$ captures the cost implied by the variability of the insured loss. From equation (1), $\gamma$ is an increasing function of $g$, with $\gamma=0$ if and only if $g=0$. It can be shown that

- The level of self-retention in this third layer is lower than that in the second layer.

- The degree of coverage using the contingent debt in the third layer is lower than that in the second layer.

- The degree of coverage using insurance is higher than that using the contingent debt in the third layer.

\subsubsection{Optimal risk-sharing rule in Layer IV}

The upper layer of risk $\left[D_{3}, x_{\max }\right]$ is the consequence of the firm's constrained debt borrowing capacity. Under this upper layer, part of the loss is transferred to the insurance company and the remaining loss is retained by the firm. The degree of coverage using insurance is given by

$$
I N S^{I V}=\frac{1}{1+\gamma} \text {. }
$$

It can be shown that:

- The level of coverage using insurance in this upper layer is higher than that under the third layer of loss.

- The degree of self-retention under this upper layer is higher than that under the third layer.

- The degree of self-retention in this upper layer is higher (lower) than that under the second layer if and only if $\gamma>(<) \beta(1+r)^{2}$.

These optimal risk-allocation arrangements among three different instrument are described in Table 1 and Figure 1. 
Table 1. Optimal risk-sharing arrangements within the layers of the risk financing structure.

\begin{tabular}{cccc}
\hline Layer & Level of self-retention & Level of contingent debt & Level of insurance \\
\hline IV & $100 \frac{\gamma}{1+\gamma} \%$ & $0 \%$ & $\frac{100}{1+\gamma} \%$ \\
III & $100 \frac{\beta(1+r)^{2} \gamma}{\gamma+\beta(1+r)^{2}(1+\gamma)} \%$ & $100 \frac{\gamma}{\gamma+\beta(1+r)^{2}(1+\gamma)} \%$ & $100 \frac{\beta(1+r)^{2}}{\gamma+\beta(1+r)^{2}(1+\gamma)} \%$ \\
II & $100 \frac{\beta(1+r)^{2}}{1+\beta(1+r)^{2}} \%$ & $\frac{100}{1+\beta(1+r)^{2}} \%$ & $0 \%$ \\
I & $100 \%$ & $0 \%$ & $0 \%$ \\
\hline
\end{tabular}

Figure 1. Optimal risk management strategy using insurance, contingent debt and selfretention, non-proportional insurance premium.

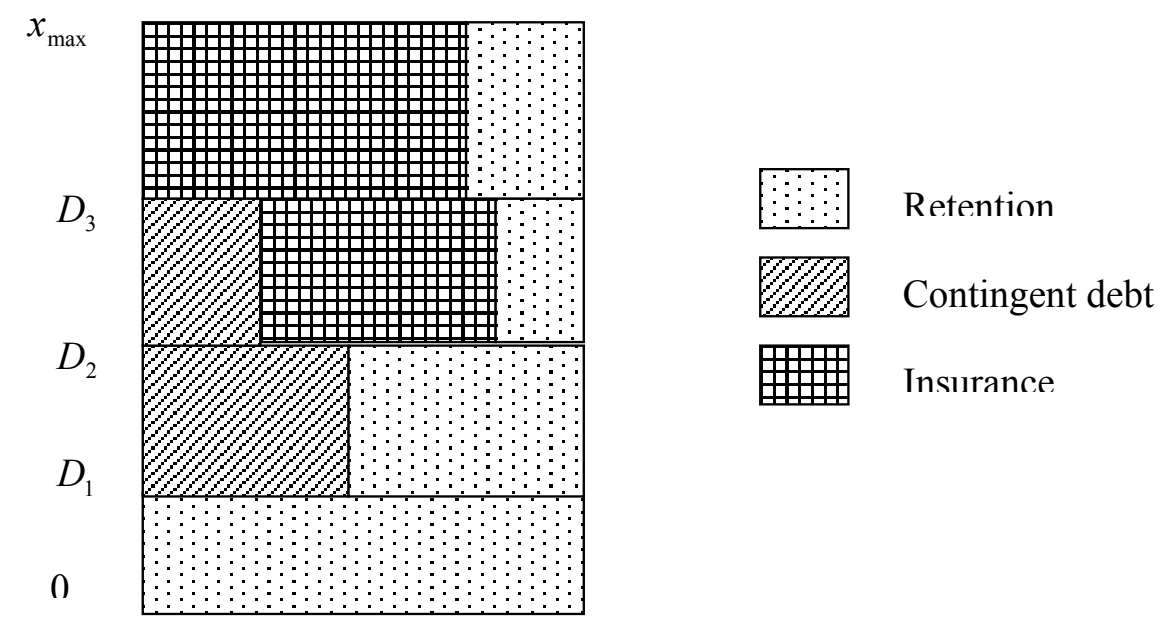

\subsection{Optimal risk-sharing rule when the insurance premium is proportional to the expected indemnity}

A particular case of interest is when the insurance premium is proportional to the expected loss. Such a pricing may be observed for non-catastrophic risks. Reconsidering the optimal indemnity schedules characterized in equations (2) to (5) with $\gamma=0$ leads to the optimal risk management strategy depicted in Figure 2. The firm retains small losses in layer I, transfers part of the losses into the next period using contingent debt in layer II, and purchases full insurance coverage for all losses higher than $D_{2}$. 
Figure 2. Optimal risk management strategy using insurance, contingent debt and selfretention, proportional insurance premium.

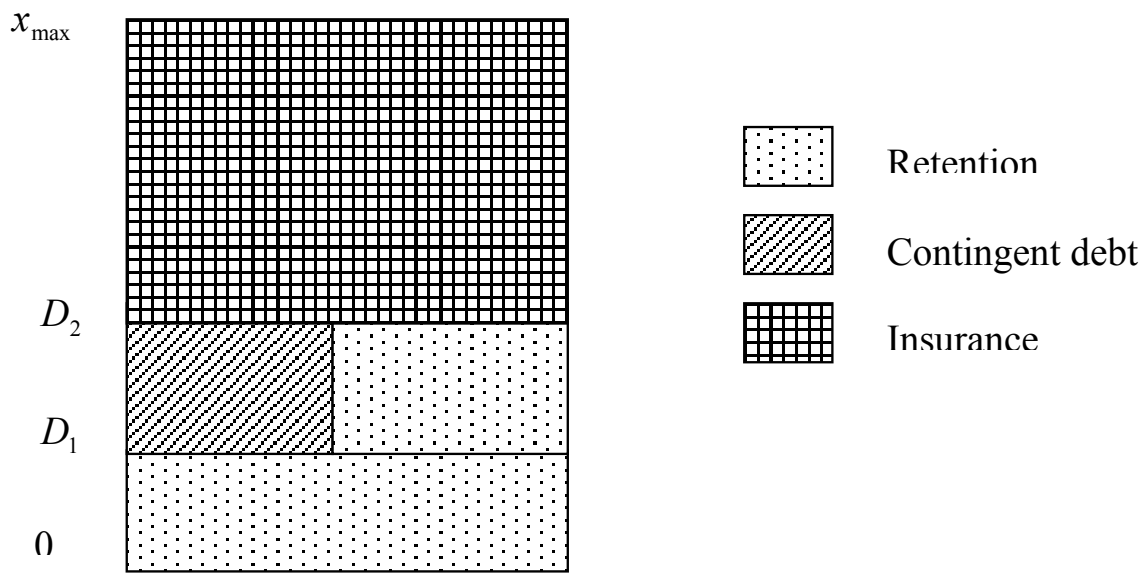

\subsection{Comparative static analysis}

Changes in the cost of insurance or contingent debt will affect both the optimal risk allocation arrangements within each layer of risk and the attachment points of each layer within the firm's base case risk financing structure. While the optimal attachments points are analytically intractable because of several (often opposite) effects at work, it is possible to tease out the direct effect of changes in pricing of different risk instruments on the risk allocation arrangements within each individual layer of risk. Below we examine the effect of four most plausible scenarios on the overall structure of the firm's risk management program, which include: (i) an increase in the risk-free interest rate; (ii) an increase in the cost of insurance; and (iii) an increase in the level of risk taken by the firm; and (iv) an increase in the borrowing capacity of the firm.

\subsubsection{Increase in the risk-free interest rate}

In this scenario, we consider an increase in the risk-free interest rate $r$ of the contingent debt. This will move up the first attachment point $D_{1}$, i.e., layer I in which the firm retains $100 \%$ of the loss, and will bring down the attachment point $D_{2}$ because the contingent debt becomes more costly. This will also move up the attachment point $D_{3}$ because the attachment point $D_{2}$ comes down and the degree of coverage financed with the contingent debt decreases. As a consequence, the borrowing constraint becomes less binding for higher levels of loss.

Within layer II, the portion of risk financed by the contingent debt is reduced, and thus the level of self-retention goes up. The fraction of the loss in layer III financed by the contingent debt is reduced, while the insurance coverage and the level of self-retention both go up. ${ }^{2}$ Finally, in the highest layer of risk the insurance coverage remains unchanged.

The impact of an increase in the risk-free interest rate is depicted in Figure 3.

\footnotetext{
${ }^{2}$ The fraction of the loss as a percentage of the total loss (all layers included) may increase, depending on the changes in the attachment points.
} 
Figure 3. Impact of an increase in the risk-free interest rate of the contingent debt on the optimal risk management strategy, non-proportional insurance premium.

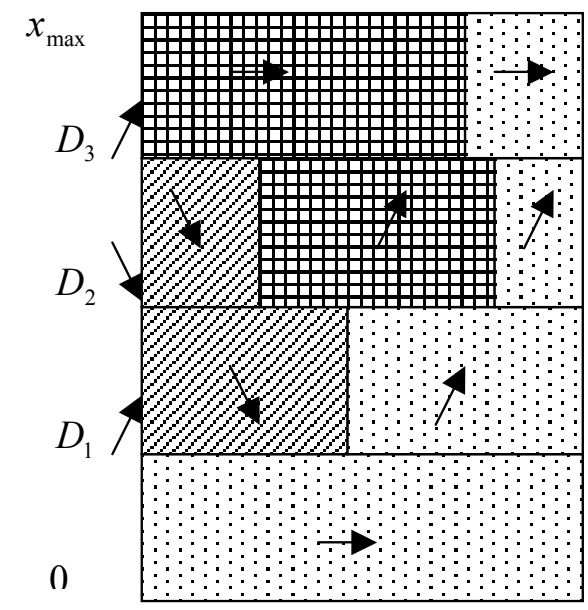

\begin{tabular}{|c|c|}
\hline$\vdots$ & Retention \\
\hline & Contingent debt \\
\hline 艮 & Insurance \\
\hline
\end{tabular}

\subsubsection{Increase in the cost of insurance}

We consider first the impact of increase in the part of the insurance premium proportional to the expected indemnity payment. As can be seen in Figure 4, the attachment points $D_{2}$ and $D_{3}$ will increase, while the lowest attachment point will be unchanged. The optimal risksharing arrangements within each risk layer remain intact .

Suppose now that the cost of volatility of the insured losses increases, i.e., $g(x)$ becomes higher for all $x$. This means that the variability of the indemnity payments becomes more costly for the insurance company and thus the insurance premium increases. Such an increase will increase the attachment point $D_{2}$ and decrease the highest attachment point $D_{3}$ (because the firm's borrowing constraint is reached sooner), while the first attachment point $D_{1}$ is unchanged. Regarding the risk-sharing rules, the following changes are observed. The fraction of the loss in layer II covered by the contingent debt remains unchanged. The coverage provided by the contingent debt, as a fraction of the loss in layer III, increases, while the insurance coverage decreases and the level of self-retention increases. Finally, the fraction of the loss in layer IV insured decreases and thus the level of self-retention increases.

Figure 4. Impact of an increase in the insurer's cost of variability on the optimal risk management strategy, non-proportional to insurance premium.

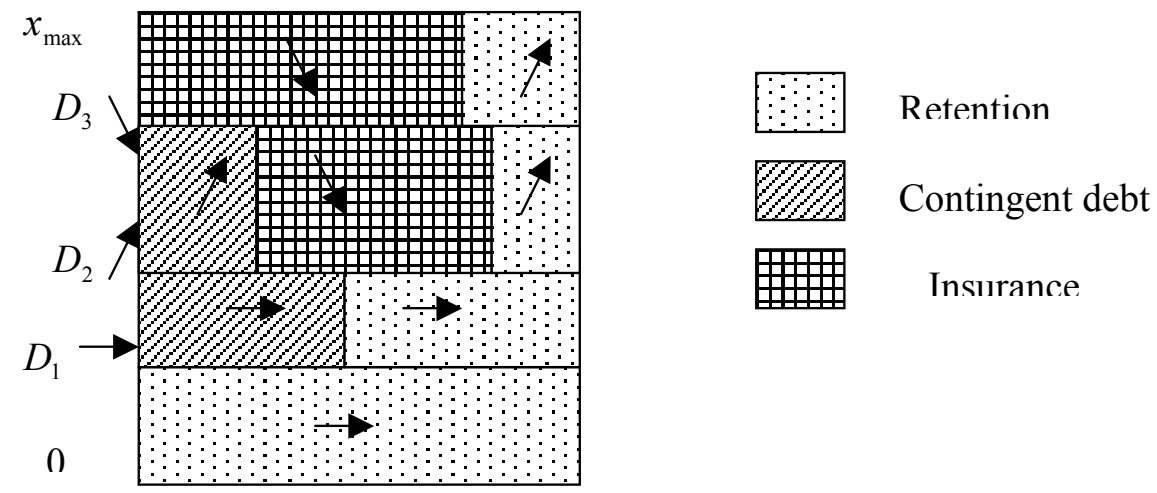




\subsubsection{Increase in the level of risk}

Our model does not allow to perform a quantitative analysis of the impact of a change in the level of risk taken by the firm on its risk financing strategy. However, we are able to propose a qualitative analysis of an increase in the variability of the loss on the optimal risk financing arrangements for each layer. An increase in risk generates two opposite effects. On the one hand, it induces the firm to increase its insurance coverage because the self-retention of risk in the first period or in the second period (through the contingent debt) becomes more costly for the risk-averse firm due to the increased amount of risk exposure for its own capital. It is called the direct risk effect. On the other hand, this increase in risk will increase the insurance premium because this will generate an additional cost for the insurer. ${ }^{3}$ The firm will thus respond by reducing its insurance coverage. It is called the premium effect. While the total effect of an increase in risk is ambiguous, it is likely that the direct risk effect is larger than the premium effect due to the portfolio effect working to the advantage of insurers. To put it differently, it becomes more costly for the firm than for its insurer to bear additional risk exposure as the firm's cost of risk increases more rapidly than the insurer's one. Under this realistic assumption, we can examine the impact of the direct risk effect on the optimal riskfinancing arrangements.

The firm should respond to such an overall risk increase by bringing down all three attachment points. This can thus be interpreted as a reduction in the insurer's cost of loss variability, with the firm's cost of the risk being unchanged. In both cases, one can observe an increase in the difference between the firm's total cost of risk and the insurer's one due to the portfolio effect. From the previous analysis of changes in the risk financing structure of the firm due to the rising cost of insurance, we infer that the impact of the increase in risk variability may affect the risk-financing rules within each four layers of the risk as follows. In layer II, the risk-sharing arrangement is unchanged. The fraction of the loss in layer III covered by insurance increases while the degree of self-retention and the degree of coverage using contingent debt decrease. In layer IV, the level of insurance coverage, as afraction of the loss within this layer, increases and consequently the degree of self-retention decreases. These changes in the optimal risk-sharing arrangements are described in Figure 5.

Figure 5. Impact of an increase in the loss variability on the optimal risk management strategy, non-proportional insurance premium.

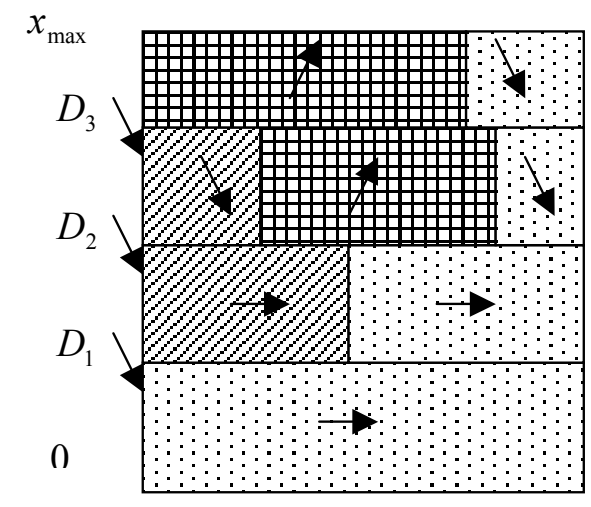

\begin{tabular}{|c|c|}
\hline$\vdots \vdots \vdots \vdots \vdots \vdots \vdots \vdots$ & Retention \\
\hline & Contingent debt \\
\hline 册册 & Insurance \\
\hline
\end{tabular}

\footnotetext{
${ }^{3}$ If the premium is proportional to the expected indemnity, then this increase in risk has no effect on the premium.
} 


\subsubsection{Increase in the borrowing capacity of the firm}

The limited borrowing capacity of the firm plays a central role in the design of an optimal risk management strategy using contingent debt and insurance. This constraint is exacerbated in the current two-period model because the firm has to fully reimburse its loan during the period following the loss. In other words, the inter-temporal risk sharing is only feasible between two periods. The attachment point $D_{3}$ is the direct consequence of this financial constraint. An increase in the borrowing capacity of the firm will generate an increase in $D_{3}$, with all other parameters remaining unchanged. In the limit case where the firm does not face such a borrowing constraint, the highest attachment point is no longer present and, consequently, all losses higher than $D_{2}$ are covered using self-retention, contingent debt and insurance (see Figure 1 with $D_{3}=x_{\max }$ ).

\section{Numerical Examples}

In this section we examine the impact of the insurance cost (and more specifically the insurer's cost due to the loss variability) on the optimal risk-financing rules within each risk layer. The cost of external capital $r$ is set at $10 \%$ and the discount factor $\beta$ is set at 0.91 .

Figures 6 shows the optimal levels of self-insurance, contingent debt and insurance in a continuum extending from a soft insurance market to a hard insurance market.

As has been shown analytically, the fraction of the loss in layers III and IV retained by the firm (level of self-retention) increases as the insurer's cost of loss variability increases. The fraction of the loss in layer III covered with the contingent debt (level of contingent debt) also increases. On the contrary, the fraction of the loss in layers III and IV covered by insurance (level of insurance) decreases.

While these numerical examples are not necessary realistic, they give interesting additional insights into the impact of the cost of insurance on the optimal risk-financing arrangements in corporations operating under the real world constraints. During a soft market, when insurance rates are low, corporations tend to prefer traditional commercial insurance market. However, when rates harden, the ART markets often prove more advantageous. This behavior is highlighted by comparing the development of catastrophe bond markets (see Figure 7) and the reinsurance price volatility (see Figure 8). One can observe that, in year 2000, the increase in reinsurance prices is associated with an increase in the volume of catastrophe bonds issued. 
Figure 6. Optimal risk-sharing rules within layers of the risk financing structure.
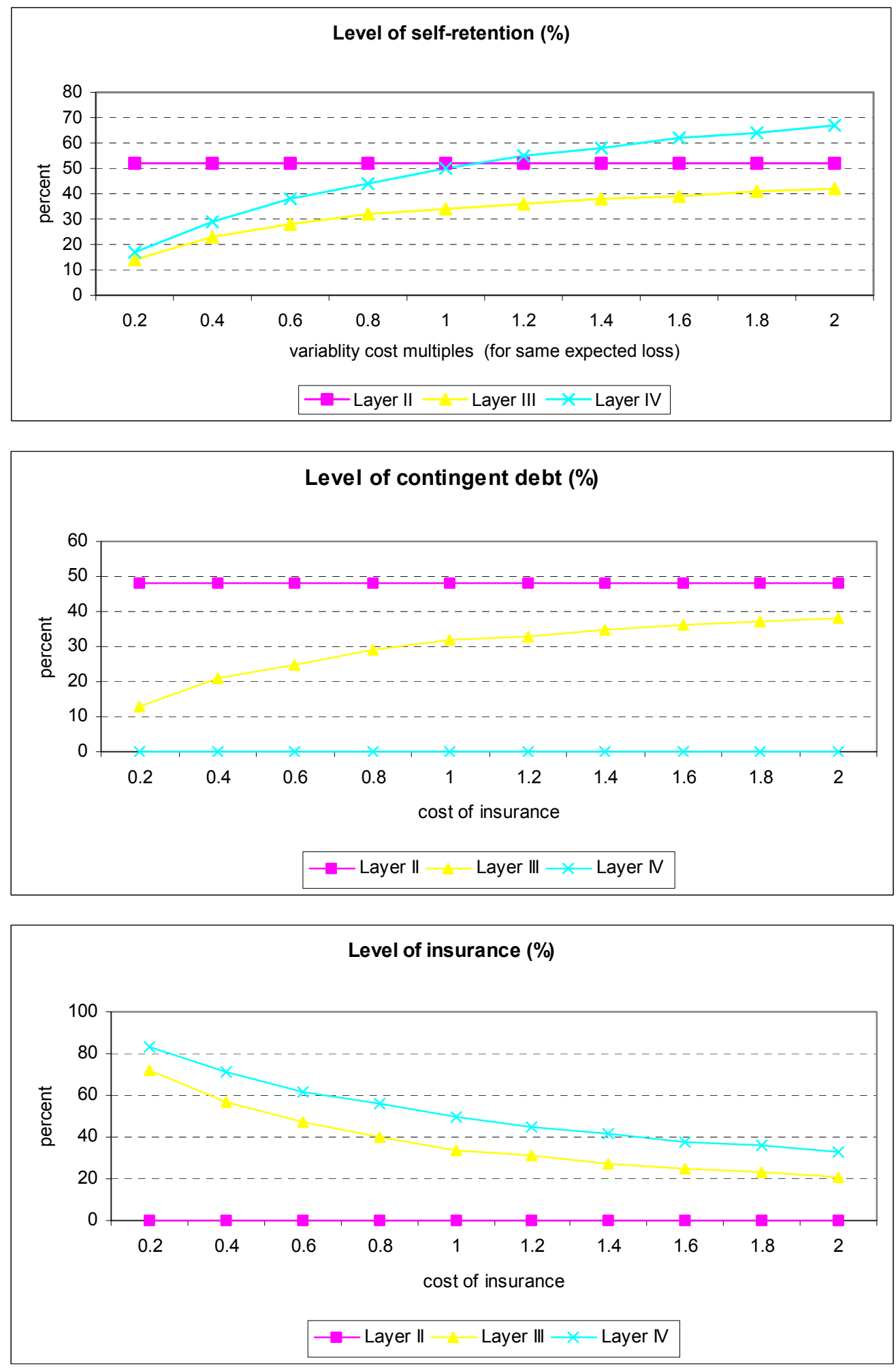
Figure 7. Catastrophe bonds issued on financial markets (Source: Cummins 2003).

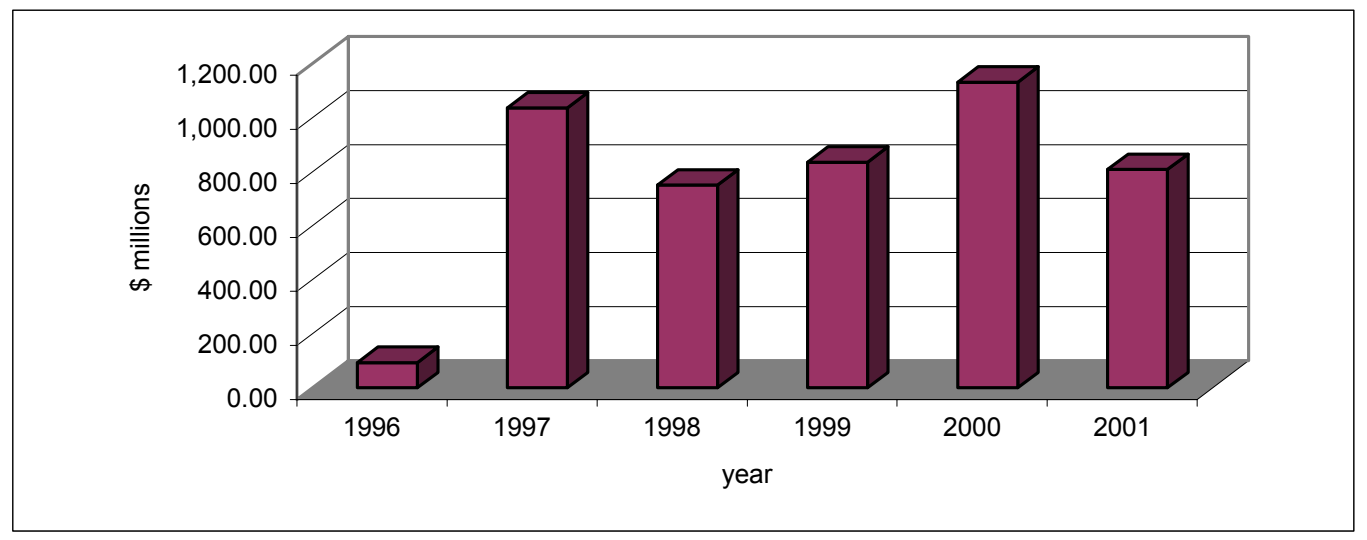

Figure 8. Reinsurance Pricing Volatility

$(1984=1.00)$

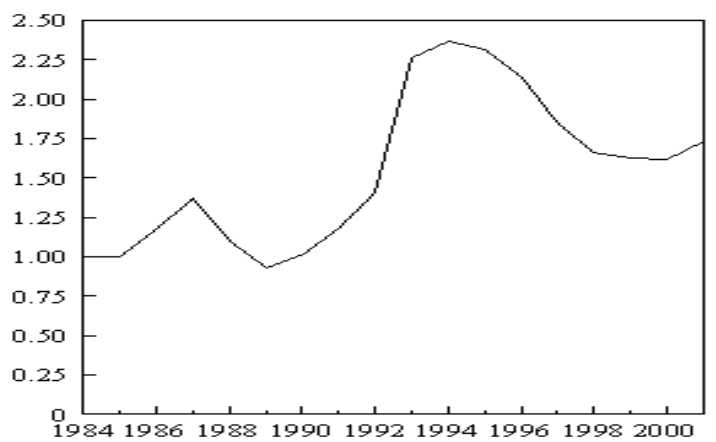

Source: Congressional Budget Office based on data from Paragon Reinsurance Risk Management Services.

\section{Conclusions}

This paper investigates optimal risk financing strategies for a firm using self-retention, insurance and contingent debt under different assumptions about pricing of these instruments. While several previous studies point out the importance of such a combination, to the best of our knowledge, this paper is the first effort to draw an analytical framework to study the underlying tradeoffs between the costs of different risk financing instruments and how they affect the choice of an optimal risk financing strategy. The flexibility of the model employed by this research allows us first to distinguish between two sets of technical parameters faced by a risk-averse firm: the attachment points for each additional layer of risk financing needed to cover the firm's risk exposure which ultimately results in a four layered structure, and the risk-financing arrangements within each risk layer. The first set of parameters, the attachment points, cannot be explicitly characterized in our model. These model limitations thus justify the use of stochastic simulation tools in further research. The focus of this paper is the second set of parameters, the optimal risk-financing rules within each layer, which are examined in detail, with an output being the explicit contract structure. By employing a plausible base case scenario risk financing structure, we analyze how changes in the costs of insurance coverage, the level of risk assumed by the firm and the borrowing constraint affect the optimal risk 
allocation among three different risk financing instruments within each layer of the risk. Using numerical examples, we also examine the cost of loss variability on the choice of an optimal risk allocation arrangements.

This paper must be viewed as a first step in a long-term research project on designing an optimal risk financing strategy using insurance, credit, and savings. The next step in this research will be to extend the capabilities of the model used in this study to allow for the use of the firm's existing stock of wealth (shareholders' equity), insurance, and its future earnings. The analytical findings of these two studies could then be combined to provide a broader conceptual analysis of the optimal risk financing strategy based on insurance, credit and savings. An interesting contribution of the current model, however, is to show the limitations of a conceptual analysis based on the conventional optimization algebra techniques thus providing an analytical justification for using stochastic simulation models in the future. These models may be particularly useful to investigate the optimal attachment points for each risk layer in the firm's overall risk financing structure and their sensitivity to the costs of the financing instruments and to the variability characteristics of the risk. By utilizing the models, we will be able to examine not only how the risk is distributed among the three risk management instruments within each layer of the financing structure (i.e., horizontal analysis), but also, how the risk is covered among the layers of the financing structure with each of the three instruments (vertical analysis). Combining the vertical and horizontal analyses will thus allow us to derive the aggregate risk allocation among the selected risk financing instruments.

The paper may also contribute to the ongoing conceptual debate on the design of optimal risk management strategies given the affordability constraints of low-income households and small businesses in the area of micro insurance as it furthers the debate originated by the recent World Bank papers emphasizing the need for simultaneously considering multiple risk financing channels (Siegel 2000) in micro insurance (Siegel, Alvang and Canagarajah 2001, Gallardo and Randawa 2003). 


\section{References}

Brown, G.W., Toft, K.B. 2002. How firms should hedge, Review of Financial Studies 15, 1283-1324.

Cochrane, J. 2001. Asset pricing. Princeton University Press.

Cummins, J. 2002. Convergence of financial services: the wholesale market. Presented at the 2002 ARIA Meeting.

Doherty, N. 2000. Innovation in corporate risk management: the case of catastrophe risk, in G. Dionne, ed., Handbook of Insurance (Kluwer Academic Publishers), 503-539.

Froot, K.A., Scharfstein, S., Stein, J.C. 1993. Risk management: coordinating investment and financing policies, Journal of Finance 68, 1629-1658.

Gallardo, J. and B. Randhawa (2003). Delivering agriculture insurance products: what is the capacity of the microfinance institutions? The World Bank, Working paper.

Greenwald, B.C., Stiglitz, J.E. 1993. Financial market imperfections and business cycles, Quarterly Journal of Economics 108, 77-114.

Jaffee, D.M., Russell, T. 1999. Financial markets and financial intermediaries: the case of catastrophe insurance. Presented at NBER Insurance Conference.

Kimball, M.S., 1990. Precautionary saving in the small and in the large, Econometrica 58, 5373.

Mahul, O., 2002. Coping with catastrophic risk: the role of (non-) participating contracts, $29^{\text {th }}$ Seminar of the European Group of Risk and Insurance Economists, Nottingham, UK.

Neumann, J. von, Morgenstern, O. 1954. Theory of games and economic behavior. Princeton University Press.

Siegel, P. (2000). Towards an integrated approach to manage risk in rural areas, Paper presented at the $26^{\text {th }}$ International conference of agricultural economists, August 13-18, 2003, Berlin, Germany.

Siegel, P., J. Alwang, and S. Canagarajah (2001). Viewing microinsurance as a social risk management instrument, The World bank, Social Protection Discussion Paper 0116.

Smith, C.W., Stulz, R., 1985. The determinants of firms' hedging policies, Journal of Financial and Quantitative Analysis 20, 391-405.

Swiss Re. 1999. Alternative Risk Transfer for Corporations: a Passing Fashion or Risk Management for the $21^{\text {st }}$ Century?, Sigma no. 2/1999.

Swiss Re. 2001. Capital market innovation in the insurance industry. Sigma no. 3/2001. 


\section{Appendix 1.}

\section{The model}

The hedging decisions of the firm are investigated in a two-period model. We assume an intertemporally separable utility function $u($.$) with discount factor (rate of impatience)$ $\beta \in(0,1)$.

In the first period, the firm is endowed with a nonrandom initial wealth $w_{0}$ subject to a risk of loss $\widetilde{x}$, with $0 \leq x \leq w_{0}$ for all $x{ }^{4,5}$ To hedge this marketable risk, the firm can purchase a reinsurance policy and/or a contingent debt. Following Arrow (1963) and Raviv (1979), the reinsurance policy is described by a couple $[I(), P$.$] , where I(x)$ is the amount of indemnity payment made by the reinsurer when the realized loss is $x$, with

$$
I(x) \geq 0,
$$

and $P$ is the insurance premium. Assuming that the insurance company is risk neutral and faces an increasing and non-concave cost function $c($.$) , with c^{\prime}>0, c^{\prime \prime} \geq 0$ and $c(0)=0$, the premium satisfies

$$
P=E[I(\widetilde{x})+c(I(\tilde{x}))]
$$

where $E$ is the expectation operator. The firm can also purchase a contingent debt that provides it with an access to capital following a loss. The amount of contingent credit is assumed to depend on the realized loss:

$$
J(x) \geq 0 \text {. }
$$

The borrower may be unable to reimburse its contingent credit the next period, thus exposing the lender to default risk on payment. This problem of default risk is left to future research. However, we assume that the amount of contingent credit is less than an exogenous upper bound $\bar{J}$ so that the probability of default of payment is zero:

$$
J(x) \leq \bar{J} .
$$

The firm pays credit guarantee fees that are assumed to be proportional to the expected value of the contingent debt:

$$
Q=n E J(\tilde{x}),
$$

with $n \geq 0$. We could assume that the indemnity functions $I($.$) and J($.$) are less than the$ realized loss. It will be shown that these conditions are always satisfied at the optimum. The profit of the firm at the end of the first period is thus

$$
\pi_{1}=w_{0}-x+I(x)-P+J(x)-Q .
$$

\footnotetext{
${ }^{4}$ The risk of loss is represented by a continuous random variable. We could assume that the random variable is distributed according to a mixture of discrete and continuous probability distributions. However, this would complicate the exposition without adding any content.

${ }^{5}$ Tildes are used to denote random variables, and the same variables without the tilde denote realizations of random variables.
} 
In the second period, the firm is endowed with a random initial wealth $\widetilde{w}_{1}$ that is assumed to be independent of the first-period random loss $\tilde{x}$. This random initial wealth may be caused by a second-period random loss that affects a certain initial wealth. ${ }^{6}$ It will reimburse (with certainty) its contingent loan contracted at the first period at a risk-free interest rate $r \geq 0$. At the end of the second period, the profit of the firm is thus

$$
\pi_{2}=w_{1}-(1+r) J(x) .
$$

It is noteworthy that this profit is unknown at the beginning of the second period because of the random contingent reimbursement $(1+r) J(\tilde{x})$ and the random initial wealth $\widetilde{w}_{1}$.

\footnotetext{
${ }^{6}$ The firm may purchase only insurance against this loss.
} 


\section{Appendix 2.}

\section{Optimal insurance and contingent debt design}

The problem of the firm is to find the payoff functions that maximize the expected discounted utility over the two periods. Formally, it solves the maximization problem

$$
\underset{I(.), J(\cdot), P, Q}{\operatorname{Max}} E u\left(\tilde{\pi}_{1}\right)+\beta E u\left(\tilde{\pi}_{2}\right)
$$

subject to conditions (A1) to (A7).

This problem is solved in two steps. The insurance premium and the credit guarantee fee are first taken as given and the optimal indemnity schedules are derived. Second, the optimal reinsurance premium and contingent fee are examined.

Following Raviv (1979), this maximization problem can be solved using optimal control theory. We show (see Appendix 4) that there exist deductibles $D_{1} \geq 0$ and $D_{2} \geq 0$ such that the optimal indemnity schedule under the insurance policy and the contingent debt satisfy

$$
\begin{aligned}
& I^{*}(x) \begin{cases}>0 & \text { for all } x>D_{2} \\
=0 & \text { otherwise, }\end{cases} \\
& J^{*}(x) \begin{cases}>0 & \text { for all } x>D_{1} \\
=0 & \text { otherwise. }\end{cases}
\end{aligned}
$$

In addition, the optimal marginal coverage functions satisfy

$$
J^{\prime *}(x)=\frac{u^{\prime \prime}\left(w_{0}-x+J^{*}(x)-P-Q\right)}{u^{\prime \prime}\left(w_{0}-x+J^{*}(x)-P-Q\right)+\beta(1+r)^{2} E u^{\prime \prime}\left(\widetilde{w}_{1}-(1+r) J^{*}(x)\right)}
$$

for all $x \in S_{2}=\{x: I(x)=0, J(x)>0\}$,

$$
I^{\prime *}(x)=\frac{u^{\prime \prime}\left(w_{0}-x+I^{*}(x)-P-Q\right)}{u^{\prime \prime}\left(w_{0}-x+I^{*}(x)-P-Q\right)-u^{\prime}\left(w_{0}-x+I^{*}(x)-P-Q\right) \frac{c^{\prime \prime}\left(I^{*}(x)\right)}{1+c^{\prime}\left(I^{*}(x)\right)}}
$$

for all $x \in S_{3}=\{x: I(x)>0, J(x)=0\}$,

$$
I^{\prime^{*}}(x)=\frac{u^{\prime \prime}\left(w_{0}-x+I^{*}(x)+\bar{J}-P-Q\right)}{u^{\prime \prime}\left(w_{0}-x+I^{*}(x)+\bar{J}-P-Q\right)-u^{\prime}\left(w_{0}-x+I^{*}(x)+\bar{J}-P-Q\right) \frac{c^{\prime \prime}\left(I^{*}(x)\right)}{1+c^{\prime}\left(I^{*}(x)\right)}}
$$

for all $x \in S_{4}=\{x: I(x)>0, J(x)=\bar{J}\}$, and

$$
\begin{aligned}
& 1-{I^{\prime}}^{*}(x)-J^{\prime^{*}}(x)=\frac{u^{\prime}\left(\pi_{1}\right)}{-u^{\prime \prime}\left(\pi_{1}\right)} \frac{c^{\prime \prime}\left(I^{*}(x)\right)}{1+c^{\prime}\left(I^{*}(x)\right)} I^{\prime^{*}}(x), \\
& 1-{I^{\prime *}}^{*}(x)-{J^{\prime *}}^{\prime *}(x)=\beta(1+r)^{2} \frac{E u^{\prime \prime}\left(\tilde{\pi}_{2}\right)}{u^{\prime \prime}\left(\pi_{1}\right)} J^{\prime *}(x)
\end{aligned}
$$

for all $S_{5}=\{x: I(x)>0, J(x)>0\}$. 
When no insurance indemnities are paid, $I^{*}(x)=0$, equation (A11) characterizes the optimal payoff of the contingent debt. The marginal payoff is less than unity, $J^{\prime *}(x)<1$, i.e., the contingent debt displays partial coverage above the deductible. When only insurance indemnities are paid, the optimal insurance indemnity schedule is solution to the differential equation (A12). The insurance contract displays partial (full) coverage above a deductible, $I^{\prime *}(x)<(=) 1$ as long as the cost function $c($.$) is convex (linear) in the claims. This case$ correspond to the standard result in the insurance literature (Raviv 1979). It is noteworthy that equations (A11) and (A12) have interesting similarities. In equation (A11), the risk sharing rule between the two parties, is driven by the cost function $c($.$) . In equation (A11), this risk$ transfer using contingent debt, i.e., the intertemporal risk sharing arrangement, is driven by its impact on the firm's welfare in the second period. When the amount of contingent debt is equal to its maximum, i.e., constraint (A4) is binding, the optimal risk sharing rule between the two parties is characterized by equation (A13), which has the same properties as equation (A12). Finally, optimal indemnities are derived from the system of differential equations (A13) and (A14) when both indemnities are positive and the amount of contingent debt is less than the upper limit. They show that total (marginal) coverage from both instruments is partial, $I^{\prime *}(x)+J^{\prime *}(x)<1$, when the insurer's cost function is convex, while it is full, $I^{\prime^{*}}(x)+J^{\prime^{*}}(x)=1$, when the cost function is linear. 


\section{Appendix 3.}

\section{Explicit characterization of optimal contract design under additional assumptions}

Under no additional assumptions, the explicit forms of the optimal contracts cannot be derived. We first make the following additional assumption: (i) the insurer's utility function is quadratic, i.e., the deadweight function is quadratic. For all $x \in S_{2}$, equation (A11) becomes

$$
J^{\prime^{*}}(x)=\frac{1}{1+\beta(1+r)^{2}} .
$$

The marginal coverage is thus lower than unity. In addition, it is lower (higher) than 0.5 if and only if $\beta>(<) 1 /(1+r)^{2}$. Observe that when the discount factor is one and the risk-free interest rate is zero, we have $J^{\prime *}(x)=0.5$; any marginal increase in the loss above the deductible is equally shared between period 1 and period 2 . There is thus a total time diversification. The higher the discount factor and/or the interest rate, the lower the marginal coverage above the deductible.

Define $\gamma(\pi, x)=\left(-\frac{u^{\prime}(\pi)}{u^{\prime \prime}(\pi)}\right) \frac{c^{\prime \prime}(I(x))}{1+c^{\prime}(I(x))}$. The function $\gamma(.,$.$) increases as the firm's tolerance$ towards risk, $-u^{\prime} / u^{\prime \prime}$, and/or the curvature of the cost function $c($.$) increase. We also assume$ that (ii) $\gamma(.,$.$) can be approximated by a constant, i.e., \gamma(\pi, x) \equiv \gamma$ for all $\pi$ and $I(x)$. Equations (A12) and (A13) become

$$
I^{\prime^{*}}(x)=[1+\gamma]^{-1},
$$

for all $x \in S_{3}$ and all $x \in S_{4}$. The optimal insurance policy thus displays partial marginal coverage above a deductible.

Under assumptions (i) and (ii), equations (A14) and (A15) become for all $x \in S_{5}$

$$
\begin{aligned}
& 1-I^{\prime^{*}}(x)-J^{\prime^{*}}(x)=\gamma, \\
& 1-{I^{\prime}}^{*}(x)-{J^{\prime *}}^{*}(x)=\beta(1+r)^{2} J^{\prime^{*}}(x) .
\end{aligned}
$$

After some straightforward manipulations, the optimal marginal payoffs are thus given by

$$
\begin{aligned}
I^{\prime *}(x) & =\frac{\beta(1+r)^{2}}{\gamma+(1+\gamma) \beta(1+r)^{2}} \\
J^{\prime *}(x) & =\frac{\gamma}{\gamma+\beta(1+r)^{2}(1+\gamma)} .
\end{aligned}
$$

Two cases must be examined depending on the levels of deductibility.

Suppose first that $0 \leq D_{1}<D_{2}$. This may occur when the cost of insurance is high compared to the cost of the contingent debt. In addition, we assume that $\bar{J}$ is sufficiently large so that $J^{\prime}(x)>0$ and $I^{\prime}(x)>0$ for some $x$. From equations (A16), (A20) and (A21), the optimal payoff under contingent debt is 


$$
J^{*}(x)=\left\{\begin{array}{l}
0 \text { for } x \leq D_{1} \\
J_{1}^{*}(x)=\frac{x-D_{1}}{1+\beta(1+r)^{2}} \quad \text { for } x \in\left[D_{1}, D_{2}\right] \\
J_{2}^{*}(x)=\frac{\gamma\left(x-D_{2}\right)}{\gamma+\beta(1+r)^{2}(1+\gamma)}+\frac{D_{2}-D_{1}}{1+\beta(1+r)^{2}} \quad \text { for } x \in\left[D_{2}, D_{3}\right] \\
\bar{J} \quad \text { for } x \geq D_{3}
\end{array}\right.
$$

where $D_{3}$ is defined such that $J_{2}^{*}\left(D_{3}\right)=\bar{J}$. The optimal indemnity schedule under reinsurance is

$$
I^{*}(x)=\left\{\begin{array}{l}
0 \quad \text { for } x \leq D_{2} \\
I_{1}^{*}(x)=\frac{\beta(1+r)^{2}}{\gamma+(1+\gamma) \beta(1+r)^{2}}\left(x-D_{2}\right) \quad \text { for } x \in\left[D_{2}, D_{3}\right] \\
I_{2}^{*}(x)=\frac{x-D_{3}}{1+\gamma}+\frac{\beta(1+r)^{2}}{\gamma+(1+\gamma) \beta(1+r)^{2}}\left(D_{3}-D_{2}\right) \quad \text { for } x \geq D_{3}
\end{array}\right.
$$

When the deductible of the contingent debt, $D_{1}$, is less than the insurance deductible, $D_{2}$, the optimal financing strategy thus is as follows. First, losses lower than $D_{1}$ are retained by the firm. Second, losses $x \in\left[D_{1}, D_{2}\right]$ are financed using the contingent debt with a payoff function $J_{1}^{*}(x)$ as expressed in equation (A22). It displays partial coverage above the deductible. Third, losses higher than $\mathrm{D}_{2}$ are financed with both contingent debt and reinsurance contracts. The contingent debt contract provides partial coverage, as expressed by the payoff function $J_{2}^{*}(x)$ in equation (A21). Observe that $J_{1}^{\prime^{*}}(x)<J_{2}^{\prime *}(x)$, i.e., the payoff function under the contingent debt is globally concave. The insurance policy displays partial coverage above the deductible, $I^{\prime *}(x)<1$. The total payoff displays partial coverage $J_{2}^{\prime *}(x)+I_{1}^{\prime^{*}}(x) \leq 1$. It is globally convex in the loss: the higher the loss the higher, but less than one, the marginal payoff. This is depicted in Figure 1 when $\gamma>0$.

The curvature of the insurance cost function has a central role to play in the design of optimal payoffs. The more sensitive the insurer to the variability of insured losses, i.e., the higher the parameter $\gamma$, the higher the marginal coverage under the reinsurance policy (equation (A23)) and the lower the marginal coverage under the continent debt (equation (A22)). 
Figure A1. Optimal insurance policy and contingent debt, under quadratic deadweight cost function and $\gamma>0$, with $D_{1} \leq D_{2} \leq D_{3}$.

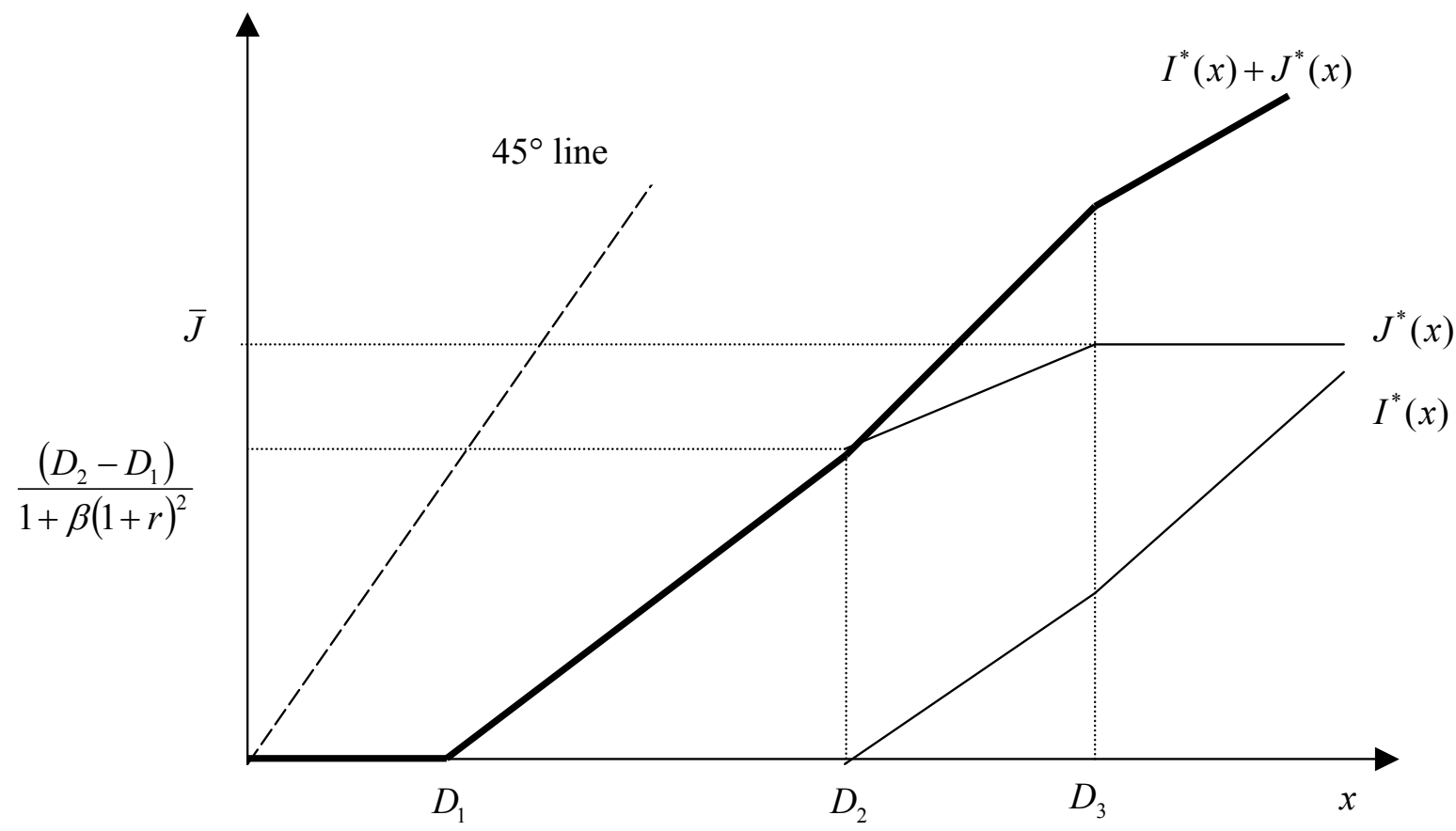

An interesting particular case is when $\gamma=0$, i.e., the insurance cost function is linear in the indemnity, $c(.) \equiv m>0$. The insurance premium is thus proportional to the expected indemnity. This means that the variance of the indemnity payoff does not affect the insurance premium. The optimal payoffs become

$$
\begin{aligned}
& J^{*}(x)=\min \left[\frac{1}{1+\beta(1+r)^{2}}\left[\max \left(x-D_{1}, 0\right)-\max \left(x-D_{2}, 0\right), \bar{J}\right]\right] \\
& I^{*}(x)=\max \left(x-D_{2}, 0\right) .
\end{aligned}
$$

The optimal payoff under the contingent debt is an excess of loss contract with a deductible (priority) $D_{1}$ and an upper limit $\left(D_{2}-D_{1}\right) /\left(1+\beta(1+r)^{2}\right)$. The optimal insurance indemnity displays full (marginal) coverage above a deductible $D_{2}$. The payoff function of the optimal hedging strategy using insurance and contingent debt thus contains three segments in the losspayoff graph: a first horizontal line, $I^{*}(x)+J^{*}(x)=0$ for all $x \leq D_{1}$, a line whose slope is less than the unity, $I^{\prime^{*}}(x)+J^{\prime^{*}}(x)<1$ with $I^{\prime^{*}}(x)=0 \quad$ and $J^{\prime^{*}}(x)=\left[1+\beta(1+r)^{2}\right]^{-1}$ for all $D_{1} \leq x \leq D_{2}$, and a line whose slope is equal to the unity, $I^{\prime *}(x)+J^{\prime *}(x)=1$ with $I^{\prime^{*}}(x)=1$ and $J^{\prime *}(x)=0$ for all $x \geq D_{2}$. The payoff function of the strategy that efficiently combines insurance and contingent debt is thus globally convex in the loss. This strategy is depicted in Figure A2 when the upper limit on the contingent debt is not binding. 
Figure A2. Optimal insurance policy and contingent debt, under quadratic deadweight cost function and linear reinsurance cost function, $\gamma=0$, with $D_{1} \leq D_{2} \leq D_{3}$.

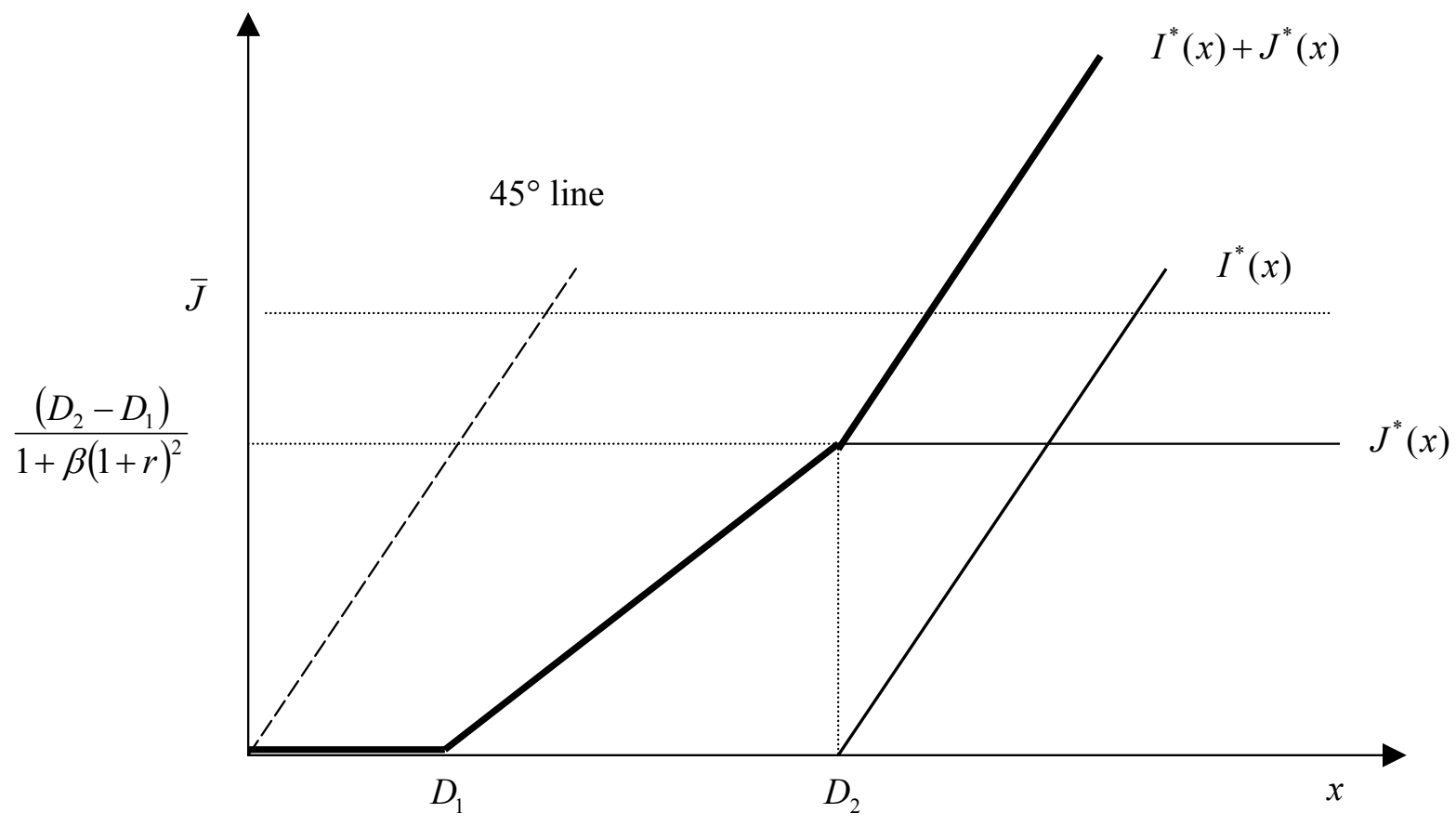




\section{Appendix 4.}

\section{Optimal indemnity schedules}

It is first noteworthy that, in the maximization problem (A8), $I^{\prime}(x)$ and $J^{\prime}(x)$ appear neither in the objective nor in the constraints. As a consequence, the Euler equation simplifies to a succession of pointwise first-order conditions for $I($.$) and J($.$) and thus problem (A8) can be$ solved using Kuhn-Tucker conditions for $I(x)$ and $J(x)$ for all $x$. The Lagangian is

(A26)

$L \equiv u\left(\pi_{1}\right)+\beta E u\left(\tilde{\pi}_{2}\right)+\lambda(x) I(x)+\gamma(x) J(x)+\Phi(x)[\bar{J}-J(x)]+\mu[P-I(x)-c(I(x))]+\delta[Q-n J(x)]$ for all $x$, with $\pi_{1}=w_{0}-x+I(x)-P+J(x)-Q, \tilde{\pi}_{2}=\widetilde{w}_{1}-(1+r) J(x)$ where $\lambda(x), \gamma(x)$, $\Phi(x), \mu$ and $\delta$ are the Lagangian multipliers associated respectively to constraints (A1), (A3), (A4), (A2) and (A5) with

$$
\begin{aligned}
& \lambda(x) \begin{cases}=0 & \text { if } I(x)>0 \\
\geq 0 & \text { otherwise, }\end{cases} \\
& \gamma(x) \begin{cases}=0 & \text { if } J(x)>0 \\
\geq 0 & \text { otherwise, }\end{cases} \\
& \Phi(x) \begin{cases}=0 & \text { if } J(x)<\bar{J} \\
\geq 0 & \text { otherwise. }\end{cases}
\end{aligned}
$$

The first-order conditions (FOC) with respect to $I(x)$ and $J(x)$ are, respectively,

$$
\begin{aligned}
& u^{\prime}\left(\pi_{1}\right)+\lambda(x)-\mu\left[1+c^{\prime}(I(x))\right]=0 \quad \text { for all } x, \\
& u^{\prime}\left(\pi_{1}\right)-\beta(1+r) E u^{\prime}\left(\tilde{\pi}_{2}\right)+\gamma(x)-\Phi(x)-\delta n=0 \quad \text { for all } x .
\end{aligned}
$$

First, one can show that because the firm is risk averse, $u^{\prime \prime}<0$, or the deadweight cost is convex, $d^{\prime \prime}>0$, and because the marginal payoff function under both contracts will be shown to be less than one, the optimal contracts satisfy equations (A9) and (A10).

Five cases must be examined depending on the realized loss $x$.

First, consider the set of realized losses $S_{1}=\{x: I(x)=0, J(x)=0\}$. No indemnities are paid under both contracts and thus the firm retains the entire loss.

Second, consider the set of realized losses $S_{2}=\{x: I(x)=0, \bar{J}>J(x)>0\}$. Differentiating the FOC (A31), with $I(x)=0, \gamma(x)=0$ and $\Phi(x)$, with respect to $x$ and rearranging yields the terms yields to

$$
\left(-1+{J^{\prime}}^{*}(x)\right) u^{\prime \prime}\left(w_{0}-x+J^{*}(x)-P-Q\right)+\beta(1+r)^{2}{J^{\prime}}^{*}(x) E u^{\prime \prime}\left(\widetilde{w}_{1}-(1+r) J^{*}(x)\right)=0 .
$$

Rearranging the terms gives equation (11).

Third, consider the set of realized losses $S_{3}=\{x: I(x)>0, J(x)=0\}$. Differentiating the FOC (A32), with $J(x)=0$ and $\lambda(x)=0$, with respect to $x$ and, from equation (A32), introducing $\mu=u^{\prime}\left(\pi_{1}\right) /\left[1+c^{\prime}(I(x))\right]$ yields 
(A33)

$$
\left(-1+I^{\prime^{*}}(x)\right) u^{\prime \prime}\left(w_{0}-x+I^{*}(x)-P-Q\right)-{I^{\prime *}}^{*}(x) u^{\prime}\left(w_{0}-x+I^{*}(x)-P-Q\right) \frac{c^{\prime \prime}\left(I^{*}(x)\right)}{1+c^{\prime}\left(I^{*}(x)\right)}=0 .
$$

Rearranging the terms gives equation (12).

Fourth, consider the set of realized losses $S_{4}=\{x: I(x)>0, J(x)=\bar{J}\}$. Differentiating the FOC (A32), with $J(x)=\bar{J}$ and $\lambda(x)=0$, with respect to $x$ and, from equation (A32), introducing $\mu=u^{\prime}\left(\pi_{1}\right) /\left[1+c^{\prime}(I(x))\right]$ yields

$$
\left(-1+I^{\prime *}(x)\right) u^{\prime \prime}\left(w_{0}-x+I^{*}(x)+\bar{J}-P-Q\right)-I^{\prime *}(x) u^{\prime}\left(w_{0}-x+I^{*}(x)+\bar{J}-P-Q\right) \frac{c^{\prime \prime}\left(I^{*}(x)\right)}{1+c^{\prime}\left(I^{*}(x)\right)}=0
$$

Rearranging the terms gives equation (A13).

Finally, consider the set of realized losses $S_{5}=\{x: I(x)>0, J(x)>0\}$. Differentiating the FOC (A32), with $\lambda(x)=0$, and the FOC (A31), with $\gamma(x)=0$, with respect to $x$ and rearranging the terms leads to equations (A14) and (A15). 